\title{
O ESTÁGIO NA FORMAÇÃO DO PROFESSOR DE SOCIOLOGIA
}

Dirce Pacheco e Zan

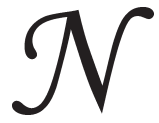

este texto, apresento algumas reflexões sobre o estágio em cursos de licenciatura, em especial, no direcionado a formação do professor de Sociologia. Desde 2002, quando da aprovação das Diretrizes Curriculares para os Cursos de Formação de Professores, ${ }^{1}$ o estágio passou a ter sua carga horária ampliada. Essa modificação criou a possibilidade de ações no sentido de ampliar a prática na formação do professor, permitindo aos estudantes a experiência com atividades do trabalho docente que vão para além da sala de aula e do conteúdo específico. Abriu, ainda, oportunidade de vivências coletivas do fazer docente. Nesse novo formato, no qual a prática e o estágio ganham lugar de destaque na formação do professor, é possível vislumbrar a possibilidade de "apropriação de amplo instrumental teóricometodológico que lhe permita investigar o processo educacional em várias de suas dimensões (...)” (Freitas, 2007, p. 4).

Ao tratar especificamente da formação do professor de Sociologia, pretendo, como nos lembra Fernandes (1976, p. 16), partir da compreensão de que

(...) mesmo na interpretação das ocorrências mais simples, o sociólogo tem que lidar com diversas variáveis, que precisam ser vistas em conjunto e que são susceptíveis de combinar-se, em situações similares, segundo esquemas não uniformes (...).

Doutora em Educação e professora do Departamento de Ensino e Práticas Culturais da Faculdade de Educação, Universidade Estadual de Campinas (UniCAmp). E-mail: dircezan@unicamp.br 
Parece ser esta a tarefa maior do sociólogo no momento em que se retoma o debate sobre a formação do professor dessa disciplina. Esse debate é em parte retomado frente à aprovação, em agosto de 2006, de Resolução do Conselho Nacional de Educação ${ }^{2}$ que torna novamente obrigatória a presença das disciplinas de Filosofia e Sociologia no currículo do ensino médio.

Considerar as diversas variáveis em seu conjunto, nesse caso, demanda problematizar a formação do professor de Sociologia no contexto da formação de professores neste país. O que aqui se propõe não é negar aspectos específicos do fazer docente em campos disciplinares distintos, mas focar o que há de comum no antigo ofício de professor.

Nos anos de 1930, quando surgiram os cursos de licenciatura no Brasil, a formação de professores era orientada pela ênfase nas disciplinas dos conteúdos específicos, reservando uma carga horária menor para a complementação pedagógica. Nesse modelo, o estágio era concebido como o momento de aplicação dos conhecimentos científicos e das habilidades pedagógicas, sendo oferecido ao final do curso (Pereira, 1999).

Mais recentemente, outro modelo vem se consolidando. Segundo Pereira (1999), trata-se de um modelo que considera o professor como sujeito autônomo, criativo e inventivo de sua prática, entendida, nesse caso, como espaço privilegiado de criação e reflexão. Nesse novo formato o estágio assume o papel de ponto de partida para a formação teórica do professor, enfatizando o contato do estudante com as instituiçôes educativas desde o início do curso.

Os limites desses modelos são analisados em trabalhos de pesquisa de vários autores que há anos se dedicam ao tema da formação de professores. No caso do modelo vigente nos anos de 1930, criticase a formação fragmentada entre teoria e prática, na medida em que se pressupõe a necessidade de formação teórica para a aplicação posterior desses conhecimentos na prática pedagógica, na situação real e concreta da sala de aula. Nesse sentido, o bom professor era compreendido como aquele que dominava o conteúdo específico de sua disciplina. Ao mesmo tempo, a supervalorização da prática, possível resultado da opção pelo segundo modelo, poderá levar à compreensão de que, para a formação do bom professor, a reflexão sobre situações do cotidiano escolar e da prática pedagógica seria suficiente (Lüdke, 2001). 
Frente às recentes transformações sociais que também provocaram reorientações no campo da educação básica, parece fundamental repensar estes dois modelos de formação e buscar a construção de um projeto pedagógico mais adequado às novas necessidades da educação brasileira.

Ao falar das mudanças recentes na educação, é possível destacar, por exemplo, a importante inclusão do ensino médio como última etapa da educação básica; a incorporação, nos textos legais, da gestão democrática e participativa como objetivo maior da administração escolar e os documentos curriculares que trazem como um de seus princípios a articulação entre os diferentes componentes curriculares. Importante destacar que estas mudanças se dão em resposta a diferentes demandas: sejam do campo social, científico ou do setor produtivo.

No caso específico da formação de professores, o documento de Diretrizes Curriculares dos Cursos de Licenciatura de 2002 apresenta orientações para possíveis ajustes a estas novas demandas. Exemplo disso está no artigo $2^{\circ}$, que recomenda que o trabalho escolar seja desenvolvido em regime de colaboração e de equipe. Além disso, aponta-se para a importância do domínio de conteúdos por parte de futuros professores, bem como do trabalho interdisciplinar. Há, neste documento, uma orientação acerca dos conhecimentos pedagógicos que precisam ser aprendidos e incorporados pelos licenciandos, com ênfase no necessário conhecimento dos processos de investigação e pesquisa, visando o aperfeiçoamento da prática do professor.

Partindo dessa compreensão é que, desde o ano de 2008, está em curso uma experiência de estágio para a formação de professores, na Faculdade de Educação (FE) da UNICAMP, que parece conter traços inovadores. Esta é uma instituição que, desde sua criação em 1972, tem contribuído para a formação de professores de diferentes áreas. Nos seus primeiros anos, foram criados cursos de licenciatura associados aos bacharelados já existentes, tendo como referência o modelo da complementação pedagógica que vigora desde os anos de 1930 .

Nos anos de 1980, os docentes desta Faculdade, vinculados à pesquisa e ao ensino em diferentes licenciaturas, esforçavam-se para viabilizar a formação do futuro professor pautada pela pesquisa e pelo diálogo entre os diferentes campos disciplinares. Importante ressaltar que, desde essa época, a proposta era garantir formação ampla do professor 
sem perder de vista sua formação específica e disciplinar. Esse movimento ficou registrado em um documento intitulado Relatos de professores de Didática e Prática de Ensino dos diferentes cursos de licenciaturas da $F E{ }^{3}$ onde é perceptível a busca por uma formação que parta de problemas práticos e concretos associados à realidade cotidiana das escolas.

Em um momento mais recente da história das licenciaturas nessa Universidade, mais especificamente em 2003, houve uma mobilização das diferentes unidades acadêmicas, indicando mudanças no regimento das licenciaturas. Este movimento orientou a deliberação do Conselho Universitário (CONSU), que "retirou a exclusividade da responsabilidade pelas licenciaturas da Faculdade de Educação" (Rosa, 2006, p. 193), passando a figurar como uma parceria entre esta Unidade e os demais Institutos que oferecem os cursos de licenciatura. Desde então, esta decisão está explicitada no Regimento Interno da Universidade. Atualmente, somente os cursos de Pedagogia e da recém-criada Licenciatura Integrada Química/Física estão sob a coordenação da Faculdade de Educação. Nesse novo contexto, mudanças curriculares foram se efetivando.

O que gostaria de destacar aqui é o caso das disciplinas de estágio no contexto dessas mudanças. A carga horária total, dedicada a essas disciplinas nos cursos de licenciatura e definida pelas Diretrizes Curriculares de 2002, é de 400 horas. No caso da UNICAMP, estas horas foram divididas entre as diferentes unidades que possuem curso de licenciatura e a Faculdade de Educação. Interessa-me aqui apresentar o trabalho que a FE vem desenvolvendo nas 200 horas de estágio em que os licenciandos estão sob sua responsabilidade.

Contando com a potencialidade deste espaço, uma vez que todos os estudantes de licenciatura da Universidade frequentam essas horas de estágio, a Faculdade optou pelo investimento na integração dos diferentes licenciandos, buscando viabilizar a experiência com outras dimensões do trabalho docente, para além da sala de aula e do conteúdo específico. De certo modo, podemos afirmar que este projeto se aproxima da concepção de educação dialógica de Freire (1987). Trata-se de uma proposta que visa, entre outras coisas, ampliar a discussão acerca da escola e da formação de professores, deslocando-a da dimensão meramente didático-pedagógica e "agregando elementos relacionados ao papel social 
atribuído ao professor na sociedade brasileira contemporânea" (Handfas, 2008, p. 5).

Nesse movimento, foi constituída a Comissão de Estágio da FE que, desde 2007, tem atuado no sentido de consolidar uma política de estágio para a Unidade, o que culminou na aprovação pela Congregação da FE do documento intitulado Para uma Política de Estágios da FE, em dezembro de 2008. ${ }^{4}$ Dentre os vários princípios norteadores do estágio que são apresentados nesse documento, merecem destaque: a) o objetivo de promover o diálogo entre as várias áreas do conhecimento e entre os diferentes níveis de educação básica; b) a organização dos trabalhos de estágio a partir da construção de projetos; c) a compreensão do estágio a partir de uma perspectiva que permita constante diálogo, construção, elaboração e ressignificação dos elementos teóricopráticos; e d) a necessidade de se ter a escola como campo de estágio imprescindível nos cursos de formação de professor, ampliando o olhar do futuro profissional para a instituição escolar e o trabalho docente. Ao mesmo tempo, almeja-se a ampliação dos campos de estágio, promovendo a vivência em instituiçóes educativas não apenas escolares. No atual momento, investimentos institucionais têm sido feitos no sentido de buscar a consolidação de projetos articulados com redes de ensino, secretarias e campos de estágio.

Muitos são os desafios presentes neste projeto. Merece destaque, por exemplo, a discordância de colegas docentes que veem nesta proposta uma possível desvalorização do conteúdo específico das diferentes disciplinas na formação dos professores. Há ainda a desconfiança de estudantes acerca da eficácia de um trabalho como este, tendo em vista que se pautam, muitas vezes, por uma concepção já estabelecida do que deveria ser o estágio, ou seja, o momento em que se aprenderiam "a dar aulas de", ou seja, o momento de aplicação do conteúdo específico aprendido até então. Trata-se, portanto, de uma concepção fundada na tradição da formação de professor fortemente presente na cultura nacional desde os anos de 1930.

É verdade que parte dessas resistências ao projeto tem sido revista em razão, principalmente, do trabalho empenhado pela Coordenação dos Cursos de Licenciaturas da FE, no sentido de possibilitar, de forma institucional, a vivência de trabalhos interdisciplinares nas atividades de estágio. Uma destas iniciativas está na organização 
dos estudantes em grupos multidisciplinares e na elaboração, juntamente com o campo de estágio, de propostas de ação que estejam articuladas ao projeto de pesquisa do professor-orientador do estágio (docente da Universidade), às demandas do campo e aos interesses dos estudantes-estagiários.

Alguns desafios permanecem no que se refere ao estágio em cursos de licenciatura. Talvez, o mais antigo deles esteja na dificuldade do estreitamento de relação com as outras unidades envolvidas na licenciatura. Desde 2003 foi criada na UNICAMP a Subcomissão Permanente de Formação de Professores, vinculada a Pró-Reitoria de Graduação, composta pelos coordenadores de todos os cursos de licenciatura e presidida por docente da Faculdade de Educação eleito pelos seus pares. Nesta instância, almeja-se promover o diálogo entre institutos e faculdades responsáveis pela formação dos professores no interior da Universidade. Este é um caminho ainda longo a percorrer, mas que estamos enfrentando com determinação.

Ao mesmo tempo em que os desafios apresentados a esta experiência de estágio são muitos, é possível vislumbrar conquistas e possibilidades que este projeto tem nos apresentado. Num primeiro momento, a sensibilização que o estágio tem promovido no sentido de reconhecimento da importância e necessidade das diferentes disciplinas na formação do estudante da educação básica. A hierarquia tradicional dos campos disciplinares muitas vezes impede que estudantes de áreas de maior destaque na escola moderna, ou seja, ciências exatas e naturais, compreendam os sentidos e finalidades de outras disciplinas como as dos campos das artes e das ciências humanas e sociais. Ir conjuntamente para a escola, com colegas de disciplinas distintas, tem provocado em muitos desses estudantes o reconhecimento da importância e dos lugares necessários para as diferentes áreas.

Além disso, a experiência tem proporcionado aos estudantes, focados não apenas no trabalho de sala de aula, a ampliação do olhar para a escola e seu entorno. Exemplo disso é a experiência de estágio vivida por grupo de estudantes dos cursos de Química, Educação Física e Ciências Sociais. Ao chegarem a uma escola pública de nível médio na cidade de Campinas (SP), ficaram incomodados com a grande quantidade de grades no prédio. Mais complexa ainda se tornava a questão para eles, quando tentaram conversar com os estudantes da escola sobre o 
assunto e notaram que eles já não as percebiam ou já as tinham incorporado em sua rotina, naturalizando a "paisagem". Foi esse então o motivador do projeto de estágio que desenvolveram, ou seja, convidar os alunos a fotografarem a escola e a refletirem, a partir de debates orientados pelos estagiários, sobre as grades ali presentes. $\mathrm{O}$ projeto resultou em encontros coletivos com uma turma de $2^{\circ}$ ano do ensino médio durante quatro semanas. Nesse período, foram apresentadas fotografias feitas pelos estudantes e posteriormente pelos estagiários. Ao mesmo tempo em que as imagens eram projetadas, os estagiários traziam referenciais que possibilitavam um aprofundamento do debate. Essa experiência, de certo modo, está em consonância com o que é proposto para o ensino de Sociologia na Proposta Curricular do Estado de São Paulo, ou seja, o professor que se aproxima do jovem para estranhar com ele o mundo e o seu próprio lugar nesse mundo. 5

Outra experiência que nos ajuda a compreender as potencialidades do projeto de estágio aqui apresentado está relacionada à demanda atual pelo trabalho integrado entre diferentes disciplinas na escola de educação básica. Com vistas a atingir esta articulação, faz-se necessário o investimento em práticas que possibilitem ao professor em formação experiências próximas a esse fazer. Nesse sentido, destaco o trabalho de um grupo de estagiários, estudantes de Ciências Sociais, Química e Matemática, que, depois de um mês e meio observando várias turmas do ensino médio de uma escola pública, propuseram trabalhar com a temática da alimentação, articulando conceitos específicos de seus campos disciplinares. $\mathrm{Na}$ elaboração do projeto, levaram em consideração os conteúdos que os professores das diferentes disciplinas estavam ensinando naquele momento e provocaram os alunos daquelas turmas de $3^{\circ}$ ano de ensino médio a refletirem acerca da alimentação numa perspectiva cultural e de mercado, explorando a história dos hábitos alimentares de membros mais velhos de suas famílias e deles próprios, além do processo de industrialização dos alimentos e a sua preparação química, garantindo uma maior durabilidade nas prateleiras dos supermercados. O trabalho foi desenvolvido pelos estagiários, de forma conjunta, nas aulas cedidas pelo professor de Sociologia.

A experiência de orientação de estágios nesta perspectiva tem revelado uma potencialidade significativa, no que se refere à provocação e incentivo do desenvolvimento de uma postura de abertura para 
a escola e seus sujeitos e para a experimentação de uma proposta integrada com os colegas de outras disciplinas. Em ambas as experiências aqui brevemente relatadas, evidencia-se a importância do trabalho articulado entre a Sociologia e outras disciplinas que poderá viabilizar uma aprendizagem com maior sentido para os jovens estudantes. O profissional formado em Ciências Sociais desenvolve, em função da base teórica e conceitual da área, uma capacidade de compreender processos sociais em sua totalidade, o que lhe permite uma atuação destacada em atividades de ensino apoiadas na interdisciplinaridade. Nos dois exemplos relatados anteriormente foi relevante a atuação dos estagiários de Sociologia.

Dessa forma, torna-se necessário pensar a formação dos professores numa perspectiva política, de valorização da profissão, na medida em que se requalifica o trabalho do professor (Arroyo, 1997). É ainda necessário investir cada vez mais na indissociabilidade entre teoria e prática, problematizando o processo social e histórico que contribuiu para a produção do conhecimento na sociedade moderna. Entendo, portanto, que o estágio é um espaço indispensável de inserção dos licenciandos no campo profissional e acadêmico, na medida em que o concebamos como espaço de diálogo e produção de conhecimento. Trata-se, desse modo, de investimento na ampliação da visão do "ser professor", buscando uma reaproximação não apenas entre áreas e níveis educacionais, mas entre múltiplos sujeitos sociais e históricos, e promovendo assim o diálogo "como encontro dos homens para a tarefa comum de saber agir (...)" (Freire, 1987, p. 80).

Os problemas educacionais brasileiros, vistos de uma perspectiva macrossociológica, apresentam-se, em grande parte, como produtos de nossa incapacidade de ajustar as instituições educacionais às diferentes funçôes psicoculturais e socioeconômicas que elas devem preencher e de criar um sistema educacional suficientemente diferenciado e plástico para corresponder, ordenadamente, à variedade do volume e ao rápido incremento das necessidades escolares do país como um todo (...). (Fernandes, 1976, p. 194)

Não podemos nos furtar a repensar a escola, e a formação de professor, no contexto atual. Frente às novas demandas sociais e às mudanças exigidas da escola, urge ampliarmos o debate acerca da formação de professores e, em especial, do professor de Sociologia que, mais recentemente, voltou a atuar na educação básica. 


\section{Notas}

1. Refiro-me aqui ao documento Diretrizes Curriculares dos Cursos de Licenciatura, publicado pelo MEC em 2002.

2. Faço referência à Resolução n. 4 do Conselho Nacional de Educação, de 16/08/2006.

3. Este documento foi organizado pelos coordenadores dos cursos de licenciatura na época - Hilário Fracalanza e Márcia Regina Brito - e foi produzido entre os anos de 1985-1986.

4. Documento disponível em: <www.fe.unicamp.br>

5. Proposta Curricular do Estado de São Paulo para a disciplina de Sociologia (2008, p. 3).

\section{Referências}

ARROYO, M. Pedagogia das relações de trabalho. Trabalho \& Educação, Belo Horizonte, n. 2, p. 61-67, ago./dez. 1997.

FERNANDES, F. Ensaios de Sociologia Geral e Aplicada. São Paulo: Pioneira, 1976.

FREIRE, P. Pedagogia do oprimido. Rio de Janeiro: Paz \& Terra, 1987.

FREITAS, R. Estágio supervisionado: espaço privilegiado de formação na licenciatura em Ciências Sociais. Trabalho Apresentado no XIII Congresso Brasileiro de Sociologia, na Universidade Federal de Pernambuco, Recife, 2007.

HANDFAS, A. Formação de professores de Sociologia: reflexões sobre diferentes modelos formativos. 2008. Disponível em: <www.unam.edu.ar/ 2008/educacion/trabajos>

LÜDKE, M. O professor, seu saber e sua pesquisa. Educação \& Sociedade, Campinas, n. 74, p. 77-96, abr. 2001.

PEREIRA, J.E.D. As licenciaturas e as novas políticas educacionais para a formação docente. Educação \& Sociedade, Campinas, n. 68, p. 109-125, dez. 1999.

ROSA, M.I.P. Fazendo uma narrativa: os caminhos das licenciaturas em uma universidade pública - cenas de uma experiência. In: BARBOSA, R.L.L. (Org.). Formação de Educadores: artes e técnicas 
O estágio na formação do professor de Sociologia

- ciências e políticas. São Paulo: Editora da Unesp, 2006. p. 189196.

SÃO PAULO. Secretaria Estadual de Educação. Proposta Curricular do Estado de São Paulo - Sociologia. São Paulo: SEE, 2008. p. 1-8.

Recebido em 25 de setembro de 2010

Aprovado em 22 de setembro de 2011 